\title{
Determinants of the medication adherence behavior among elderly patients with coronary heart diseases
}

\author{
Hsien-Jy Ma ${ }^{1,2}$, Miaofen Yen ${ }^{3}$, Ching-Huey Chen ${ }^{* 3}$ \\ ${ }^{1}$ Deputy Superintendent, Dou-Liou Branch Hospital, Taiwan \\ ${ }^{2}$ Associate Director of Nursing Department, Dou-Liou Branch Hospital, National Cheng Kung University Hospital, Taiwan \\ ${ }^{3}$ Institute of Allied Health Sciences and Department of Nursing, National Cheng Kung University, Taiwan
}

Received: March 24, 2015

DOI: $10.5430 /$ jnep.v5n7p38
Accepted: April 13, $2015 \quad$ Online Published: April 27, 2015

URL: http://dx.doi.org/10.5430/jnep.v5n7p38

\begin{abstract}
Background: Coronary heart disease (CHD) is one of the most common chronic diseases among elders, and lifelong medication is necessary for them to control the disease. More than $60 \%$ of elders fail to adhere to their medication regimen. The purpose of this study was to explore the determinants of medication adherence behavior (MAB) of elderly with CHD.

Methods: A cross-sectional correlation design was used. Convenience sampling was used to enroll subjects from the outpatient department of a cardiovascular clinic in a medical center in southern Taiwan. The study consecutively recruited 241 patients over 65 years old with CHD under medication for over one year and expected to take medication for life. A structured questionnaire and face to face interview was applied for data collection. The questionnaire which was developed by the researchers included a demographic sheet and five scales to measure perceived effects, perceived partnership, perceived reality, interpersonal influence, and medication-taking behaviors.

Results: Only perceived effects and interpersonal influence remained in the predicting model and both factors accounted for $17 \%$ variance of the MABs.

Conclusions: How the elderly perceive the effect of the medication and how they are influenced by others are two important determinants for medication adherence in elderly with CHD. Also, Clinical nurses can play a key role in the process of educating elderly patients so that they can achieve regular medication adherence.
\end{abstract}

Key Words: Medication behavior, Elderly, Coronary heart diseases

\section{INTRODUCTION}

Since 1993, Taiwan has become an aging society. At the end of 2013, the population aged 65 years and older had reached $11.5 \%$ and is projected to reach $20 \%$ in $2025 .{ }^{[1]}$ Due to the high prevalence of chronic diseases and continuous deterioration caused by aging, the elderly population consumes the largest portion of medical care and expenditures. According to government statistics, over $76 \%$ of the elderly had at least one chronic disease, and the highest por- tion $(25.71 \%)$ was related to circulation system disorders. ${ }^{[1]}$ Heart diseases associated with circulatory diseases were the second leading cause of death in Taiwan. ${ }^{[2]}$ Nonadherence to medication has been verified by previous studies to be associated with an increase in morbidity and mortality rate in coronary artery disease. ${ }^{[3-5]}$ The medication nonadherence rate in older patients has been wide, ranging from $4 \%$ to $90 \%$ depending on the methodology that measured adherence and the treatment purpose. ${ }^{[5-8]}$ In Taiwan, findings from

*Correspondence: Ching-Huey Chen; Email: sugar@mail.ncku.edu.tw; Address: Institute of Allied Health Sciences and Department of Nursing, National Cheng Kung University, Taiwan. 
one study exploring the medication adherence rate among older people with hypertension indicated that over $40 \%$ of older patients did not adhere to their medication regimen. ${ }^{[9]}$ With the increasing number of older patients with circulation problems, in order to maximize effects of medical treatment and to minimize waste of medical resources, it will be our continuous challenge to enhance the medication adherence rate among chronically ill elderly patients.

Previous review articles have suggested that medication adherence behaviors (MABs) were complicated and affected by many factors such as demographic characteristics, including age, race, gender, educational background, economic status, individual physical and mental condition, cognitive status, social support resources, and illness condition. ${ }^{[10-13]}$ Other factors such as number of medications, dosage form, cost of medication, insurance status, perception and belief about illness, and communication quality between patient and physician were also shown to have a relationship with MABs among elderly patients. ${ }^{[13-15]}$ Moreover, medical personnel's professional capability, attitudes, and their relationship with patients also play an important role. ${ }^{[16,17]}$

Ryan $^{[18]}$ conducted a systemic review to investigate theories of the MAB in older adults and listed the theories most frequently studied, as follows: PRECEDE (an acronym for predisposing, reinforcing, and enabling causes in educational diagnosis and evaluation), health locus of control, health decision model, and health belief model. However, all these theories overlooked the social-interaction factor that affects medication behaviors of the elderly. Most studies tend to reflect a medical professional's point of view toward the medication behavior of elderly patients and lack a description of the process of behavioral transition of carrying out the doctor's prescriptions. ${ }^{[19]}$ In order to ensure elderly patients take the medication according to their doctor's prescription, it appears necessary to look at the medication behavior from the perspective of the patient.

\subsection{Purpose of the study}

Our specific aims were to describe medication adherence status and its determinants in elders with coronary heart disease (CHD). The findings may guide health professionals to design valid interventions to enhance medication adherence in elders with CHD.

\subsection{Conceptual framework}

The medication-taking behavioral model for elderly patients with chronic disease developed by Chen, Wu, Yen, $\&$ Chen $^{[6]}$ was used as the conceptual framework for this study. This model was developed based on the medicationtaking experience among the elderly with cardiovascular diseases. The model proposed that the MABs of elderly patients with chronic diseases are affected by four major concepts-perceived effects, perceived partnership, perceived reality, and interpersonal influence. Perceived effects refer to patients' perceptions of the effectiveness of the medication in dealing with the discomforts they are most concerned about without any unbearable side effects. Perceived partnership is the patients' perception of trust in their relationship with their health professionals. Perceived reality represents the discrepancy between the patients' perception and the actual purpose of the medication treatment. Interpersonal influence means the information patients receive from friends or relatives that affects the decision of medication-taking behaviors. These four concepts interact with each other to motivate the readiness of the individual in taking action in medication adherence. While elders are ready to adhere to the medication regimen, there are facilitating factors and inhibiting factors that may enhance or hinder their medication-taking behavior. Because these two factors involve more complicated environmental and interpersonal elements, they were not investigated in the current study. Eight demographic characteristics that were reported in previous studies as having influence in MABs among elders were included in the model: age, gender, educational background, marital status, insurance status, perceived economic status, duration of disease, and other chronic comorbidity.

\section{Methods}

\subsection{Design, sampling, and subjects}

This was a cross-sectional correlational study. Convenience sampling was used to enroll subjects from the outpatient department of a cardiovascular clinic in a medical center in southern Taiwan. The patients recruited in this study have the following characteristics: they were 65 years or older and were diagnosed with CHD. Moreover, they have been under medication for over one year and are expected to take medication for life. Furthermore, they were able to communicate in either Mandarin or Taiwanese.

\subsection{Ethical considerations}

Permission to conduct this research was obtained from the institutional review board of the participating hospital. Data collection was conducted after receiving subjects' signed consent form. Subjects were informed that if they felt uncomfortable or tired, they were free to terminate their interview or to withdraw from the study at any time without influencing their medical rights.

\subsection{Data collection}

A structured questionnaire, which included a demographic sheet and five scales, was developed by the researchers for 
data collection. Eligible participants were referred by physicians from the hospital's out-patient department of cardiology. After giving their consent, the participants were invited to a quiet space in the cardiovascular clinic and requested to fill out the questionnaire themselves or through a face-toface interview. Each participant took 20 to 30 minutes to complete the questionnaire.

\subsection{Instruments}

The structured questionnaire, which was developed by the authors, included a demographic sheet and five scales to measure (a) perceived effects, (b) perceived partnership, (c) perceived reality, (d) interpersonal influence, and (e) medicationtaking behaviors. The demographic information sheet included age, gender, educational background, marital status, insurance status, perceived economic status, and illness condition. "Perceived economic status" was used to indicate financial status of the participants. Participants were asked to select among three categories that best describe their financial status: satisfactory, just enough, or insufficient.

Based on the qualitative data of the Chen et al. study (2007), the four scales were developed to measure perceived effects (9 items), perceived partnership (14 items), perceived reality (8 items), and interpersonal influence ( 8 items). A 5 -point Likert scale was applied to measure the level of agreement on each item, from totally agree (5) to totally disagree (1). Higher scores meant that participants perceived greater effectiveness and fewer side effects of their medications, perceived more trusting and collaborating relationship with their healthcare providers, perceived more understanding and acceptance of the necessity of taking the medications, and perceived more positive influences from others about taking their medications. Content validity of these four instruments was provided by nine invited experts including five gerontological nursing specialists, one cardiologist, two geriatric doctors, and one expert in health education. The importance, appropriateness, and clarity of each item were determined by using a 4-point Likert scale. All items were graded 3 points or higher by the experts. Meanwhile, 10 elderly patients with CHD were invited to test the clarity and comprehensibility of the questionnaire. The internal consistency (Cronbach's alpha) of the perceived effects scale, the perceived partnership scale, the perceived medical reality scale, and the interpersonal influence scale were $0.59,0.90$, 0.54 , and 0.66, respectively, and the two-week test re-test reliability were $0.81,0.98,0.97$, and 0.99 , respectively.

The medication adherence behaviors scale was based on the "medication adherence behaviors evaluating scale" developed by $\mathrm{Hu}$, Tseng, Tai, and Chao ${ }^{[20]}$ for use among elderly patients with hypertension. Permission to modify the instru- ment to fit this study's disease diagnosis was obtained by the researchers from Hu et al. ${ }^{[20]}$ The instrument contains 10 questions related to behaviors of taking medications. A 5-point Likert scale was designed to measure the frequency of each medication-taking behavior, from 5 points (every day) to 1 point (never). Higher scores indicate better MABs. Cronbach's $\alpha$ was 0.76 in Hu et al.'s study and 0.72 for this study sample.

\section{RESULTS}

\section{Demographic description}

After collection, data were coded, filed, and proofread with SPSS for Windows 10.0. Results were first analyzed variable by variable with descriptive statistics, and then analyzed with inferential statistics for the correlations among the variables.

As shown in Table 1, of the 241 participants, the average age was 74.3 , of whom 147 were male $(61 \%)$ and 94 were female (39\%). Their educational backgrounds ranged from illiterate to college graduate, with an average of 5.56 years of schooling, indicating that most of the participants had attained elementary school graduation only. Most participants were married and living with their spouses (81.7\%). Owing to implementation of the national health insurance program, $97.9 \%$ were insured. Most claimed they were financially sufficient (51.9\%). CHD had been diagnosed for 1 to 60 years among the participants, with an average of 7.73 years. Besides CHD, nearly $25 \%$ of the participants had other chronic disease complications, the top two of which were hypertension and diabetes.

Scores for perceived effects, perceived partnership, perceived medical reality, and interpersonal influence were transformed linearly into a 5-to-1 Likert-type scale, with 5 indicating total agreement and 1 total disagreement (negative questions were scored in reverse). For these elderly patients, the mean score for the perception of medication effects was 3.72 (SD $=0.64$ ), which lay between agreement and no comment. The mean score for the perceived partnership scale was 4.17 (SD $=0.61$ ), which indicated a strong trust relationship between the participants and their providers. The mean score for perceived reality was 3.58 ( $S D=0.93)$, demonstrating that these elderly patients tended to realize the necessity of long-term adherence to their medication regimen. As for interpersonal influence, the mean score was 3.52 ( $\mathrm{SD}=0.83$ ), showing that the people around our participants were inclined to provide positive influence on their MABs. The mean score for the total medication adherence behaviors scale was 4.77 ( $\mathrm{SD}=$ 0.52 ), indicating that these elderly patients followed their doctors' prescribed medication orders 5-to-6 days a week, or even for the whole week. 
Table 1. Demographic data of study participants $(\mathrm{N}=241)$

\begin{tabular}{|c|c|c|c|c|c|}
\hline Variables & N (\%) & Mean Years & SD & Maximum Years & Minimum Years \\
\hline Age & & 74.3 & 6.09 & 95 & 65 \\
\hline Education & & 5.56 & 4.63 & 16 & 0 \\
\hline None & $75(31.1)$ & & & & \\
\hline Illiterate (1-6 years) & $108(44.8)$ & & & & \\
\hline Primary School (7-9 years) & $23(9.5)$ & & & & \\
\hline High School (10-12 years) & 19 (7.9) & & & & \\
\hline College and above (13-16 years) & $16(6.6)$ & & & & \\
\hline \multicolumn{6}{|l|}{ Marital Status } \\
\hline Married & 197 (81.7) & & & & \\
\hline Other (single, widow, widowed) & $44(18.3)$ & & & & \\
\hline \multicolumn{6}{|l|}{ Insurance Status } \\
\hline Yes & $236(97.9)$ & & & & \\
\hline None & $5(2.1)$ & & & & \\
\hline \multicolumn{6}{|l|}{ Perceived Economic Status } \\
\hline Satisfactory & $109(45.2)$ & & & & \\
\hline Just enough & 125 (51.9) & & & & \\
\hline Insufficient & $7(2.9)$ & & & & \\
\hline Duration of CHD & & 7.73 & 7.85 & 60 & 1 \\
\hline \multicolumn{6}{|l|}{ Other Chronic Diseases } \\
\hline Hypertension & $55(22.8)$ & & & & \\
\hline Diabetes Mellitus & 48 (19.9) & & & & \\
\hline Kidney Disease & $6(2.5)$ & & & & \\
\hline Cancer & $3(1.2)$ & & & & \\
\hline Arthritis & $5(2.1)$ & & & & \\
\hline Parkinson’s Disease & $2(0.8)$ & & & & \\
\hline Other (CVA, GI, etc.) & $31(13.0)$ & & & & \\
\hline
\end{tabular}

Note. $\mathrm{SD}$ = Standard Deviation; CHD = Coronary Heart Disease; CVA = Cerebrovascular Accident; GI = Gastrointestinal.

Table 2 shows that the MABs of our participants did not as- .37). Further, according to stepwise regression analysis, only sociate with the demographic characteristics but were signifi- interpersonal influence and perceived effects showed significantly associated with perceived effects $(r=.17)$, perceived cant results, and both factors accounted for $17 \%$ variance of medical reality $(r=.25)$, and interpersonal influence $(r=$ the MABs (see Table 3).

Table 2. Relationships among the participant demographics and the factors explored in the study

\begin{tabular}{|c|c|c|c|c|c|c|c|c|}
\hline & $\begin{array}{l}\text { Medication } \\
\text { Adherence } \\
\text { Behavior }\end{array}$ & Age & Education & $\begin{array}{l}\text { Duration of } \\
\text { Disease }\end{array}$ & $\begin{array}{l}\text { Perceived } \\
\text { Effect }\end{array}$ & $\begin{array}{l}\text { Perceived } \\
\text { Partnership }\end{array}$ & $\begin{array}{l}\text { Perceived } \\
\text { Reality }\end{array}$ & $\begin{array}{l}\text { Interperson } \\
\text { al Influence }\end{array}$ \\
\hline Medication & & & & & & & & \\
\hline $\begin{array}{l}\text { Adherence } \\
\text { Behavior }\end{array}$ & 1.00 & -.02 & .01 & .3 & $.17^{*}$ & .07 & $0.25 *$ & $.37^{*}$ \\
\hline Age & & 1.00 & $-.22 *$ & $.22 *$ & .01 & .01 & $0.19 *$ & .08 \\
\hline Education & & & 1.00 & $.20 *$ & .4 & $.19 *$ & $0.17^{*}$ & .11 \\
\hline $\begin{array}{l}\text { Duration of } \\
\text { Disease }\end{array}$ & & & & 1.00 & .28 & .43 & $0.24 *$ & .11 \\
\hline Perceived Effect & & & & & 1.00 & $.17^{*}$ & $0.22 *$ & -.2 \\
\hline $\begin{array}{l}\text { Perceived } \\
\text { Partnership }\end{array}$ & & & & & & 1.00 & $0.24^{*}$ & $.30 *$ \\
\hline Perceived Reality & & & & & & & 1.00 & $.30 *$ \\
\hline $\begin{array}{l}\text { Interpersonal } \\
\text { Influence }\end{array}$ & & & & & & & & 1.00 \\
\hline
\end{tabular}

$* p<.05$. 
Table 3. Stepwise regression analysis of medication adherence behavior of the study participants

\begin{tabular}{lllllll}
\hline Variables & $\mathbf{B}$ & $\boldsymbol{R}^{2}$ & $\boldsymbol{R}^{2}$ change & SE & Beta & $\boldsymbol{t}$ \\
\hline Constant & 39.96 & & & 1.27 & & 31.48 \\
Interpersonal Influence & 0.28 & 0.14 & 0.14 & 0.04 & 0.37 & $6.31^{*}$ \\
Perceived Effect & 0.17 & 0.17 & 0.03 & 0.60 & 0.18 & $2.95^{*}$ \\
\hline
\end{tabular}

$* p<.05$

\section{Discussion}

This study showed that the MABs of our elderly participants had no relationship with their demographic characteristics, including age, gender, educational background, marital status, insurance status, and economic status. This finding was different from two previous studies, ${ }^{[21,22]}$ both of which indicated that economic status and MABs are highly correlated. The reason for this contradictory finding may be owing to our national health insurance program in Taiwan. In our study, $97.9 \%$ of the participants were insured, indicating that personal economic status may not be an obstacle for them in receiving medications. In addition, $97.1 \%$ of the participants claimed that they were economically self-sufficient.

The mean score of the MABs in this study of 4.77 was higher than Hu et al.'s finding of 4.0. ${ }^{[23]}$ That study focused only on patients with hypertension, while ours was aimed at patients with CHDs. Additional investigations are needed to compare the differences in medication adherence behavior among patients with different chronic diseases and also the reasons behind the divergence. As to the medication-taking behavioral model for elderly patients with chronic disease of Chen et al., ${ }^{[6]}$ the current study findings partially support that model by showing that the MABs were significantly correlated with three main concepts: perceived effects, perceived reality, and interpersonal influence. The possible reason that perceived partnership was not supported by our findings is that our participants generally reported great acceptance of their physicians. A previous study indicated that a trusting, harmonious relationship with physicians may improve patients' MABs. ${ }^{[24]}$ Further studies may need to recruit subjects from different hospitals to increase the variance of the patient-physician relationship.

Further regression analysis indicated that only perceived effect and interpersonal influence remained in the predicting model and that interpersonal influence is the most decisive factor of MABs. The influence may come from healthcare professionals, friends, relatives, or mass media. Nurses play a crucial role on the clinical healthcare team and should not overlook our influence on patients' medication behaviors while also continuously evaluating their sources of medication knowledge and attitude. A recent study in elderly hypertensive cohorts by Rajpura and Nayak ${ }^{[13]}$ suggested that patients' perception of diseases and beliefs about medication are important factors in their medication compliance behavior. Although Rajpura and Nayak did not study the perception of medication effects directly, as we did, both studies point out the importance of the patients' own perceptions in adhering with the medication prescriptions. As medical professionals, we should not only provide elderly patients the information we think is meaningful or important, but we must recognize these patients' concerns and perceptions about taking their medications. We also should continuously assess the possible side effects of long-term medication use and try to relieve patients' discomfort before they arbitrarily stop using the medication in an effort to ease their own suffering.

There are apparently other vital factors that may influence MABs that we did not investigate in the current study. Two factors that were included in Chen et al.'s 2007 model, ${ }^{[6]}$ facilitation factors and inhibition factors, were not examined in this study. Many interventions have been suggested as effective strategies in managing the barriers and facilitating improvement of the MABs among elderly patients. For example, van Dulmen et al. ${ }^{[21]}$ in their review study concluded that simplifying the medication regimen was one of the most effective strategies. Current study focused on examining the factors that may influence elderly CHD patients in their cognitive preparation in conducting MAB, our findings support that Chen et al.'s model can be used to quid the development of education programs to promote elderly patients' MABs.

\section{Limitations of the study}

This study was conducted only in a large medical center, and hospital characteristics should be considered when generalizing results. In addition, because this study used convenience sampling, and a majority of the participants reported being highly adherent in their medication behavior, the possibility of selection bias should also be considered. Further, data were collected at the out-patient department, where most of the participants paid regular visits to the hospital, so this research might not be applicable to those who do not make regular hospital visits or receive follow-up care. Lastly, the scales used to measure the variables (perceived effect, perceived partnership, perceived reality, and interpersonal in- 
fluence) were newly developed specifically for this study. Except for the perceived partnership scale, the internal consistency scores, Cronbach's $\alpha$, were all lower than .7, which may influence the validity of the study results. For further examination of these variables, the reliability of the measures should be improved first. In spite of these limitations, this study has unfolded a new perspective in the study of MABs among elders with chronic disease.

\section{Conclusion}

The findings of this study indicate that perceived effect and interpersonal influence are important determinants for medication adherence in elderly patients with CHD. This research will again remind healthcare professionals that while assisting elderly patients with their medication, they should try to intensify their understanding of the effects of taking medication; meanwhile, it is important to pay attention to the patients' influences and reference group and step in whenever it is necessary to clear up misunderstandings, and strengthen a rational basis for medication so as to enable the patients to coexist with the illness.

\section{ACKNOWLEDgements}

This work was supported by the National Cheng Kung University Hospital. The authors sincerely thank all the elders who participated in the study.

\section{CONFLicts OF INTEREST Disclosure}

The authors declare that there is no conflict of interest statement.

\section{REFERENCES}

[1] Ministry of the Interior, ROC. Survey summary of senior citizen condition in the Taiwan-Fuchien area [Internet]. Department of Statistics. 2015. Avaliablie from: http://sowf .moi.gov.tw/stat/month /elist.htm

[2] Ministry of Health and Welfare, ROC. Main causes of death of the elderly in Taiwan [Internet]. Department of Statistics. 2015. Avaliablie from: http://www.mohw.gov.tw/cht/DOS/Statis tic.aspx?f_list_no $=312 \&$ fod_list_no $=2747$

[3] Gehi AK, Ali S, Beeya N, et al. Self-reported medication adherence and cardiovascular events in patients with stable coronary heart disease. Arch Intern Med. 2007 Sep; 167(16): 1798-803. PMid:17846400 http://dx.doi.org/10.1001/archinte.167. 16.1798

[4] Maddox TM, Ho PM. Medication adherence and the patient with coronary artery disease: Challenges for the practitioner. Curr Opin in Cardiol. 2009 Sep; 24(5): 468-72. PMid:19550308 http://dx.d oi.org/10.1097/HCO.0b013e32832ed62d

[5] Ho PM, Magid DJ, Sheterly SM, et al. Medication nonadherence is associated with a broad range of adverse outcomes in patients with coronary artery disease. Am Heart J. 2008 Apr; 155: 77279. PMid:18371492 http://dx.doi.org/10.1016/j.ahj . 200 7.12 .011

[6] Chen $\mathrm{CH}$, Wu JR, Yen M, et al. A model of medication taking behavior in elderly individuals with chronic disease. J Cardiovasc Nurs. 2007 Sep-Oct; 22(5): 359-65. PMid:17724416 http: //dx.doi.org/10.1097/01. JCN.0000287029.87746.58

[7] Osterberg L, Blaschke T. Adherence to medication. N Engl J Med. 2005 Aug; 353(5): 487-97. PMid:16079372 http://dx.doi.org /10.1056/NEJMra050100

[8] Wu JR, Moser DK, Tennie TA, et al. Factors influencing medication adherence in patients with heart failure. Heart Lung. 2008 Jan-Feb; 37(1): 8-16. PMid:18206522 http://dx.doi.org/10.1016/j.h rtlng. 2007.02.003

[9] Lin YP, Huang YH, Yang YC, et al. Adherence to antihypertensive medications among the elderly: A community-based survey in Tainan City, southern Taiwan. Taiwan Geriatric Gerontology. 2007; 2(3): 176-89.

Published by Sciedu Press
[10] Alexa ID, Stoica S, Burca P, et al. Non-compliance in a large population of elderly patients with cardiovascular disease. J Clin Med. 2006; 1(3): 4-18.

[11] Baroletti S, Dell'Orfano H. Medication adherence in cardiovascular disease. Circulation. 2010; 121: 455-58. PMid:20351303 http: //dx.doi.org/10.1161/CIRCULATIONAHA.109.904003

[12] Dunbar-Jacob J, Bobacbick P, Mortimer MK, et al. Medication adherence in persons with cardiovascular disease. J Cardiovasc Nurs. 2003 Jul-Aug; 18(3): 209-18. PMid:12837011 http://dx.doi.o rg/10.1097/00005082-200307000-00006

[13] Rajpura JR, Nayak R. Role of illness perceptions and medication compliance of elderly hypertensive cohorts. J Pharm Pract. 2014 Feb; 27(1): 19-24. PMid:23828839 http://dx.doi.org/10.1177/0 897190013493806

[14] Ho PM, Bryson CL, Rumsfeld JS. Medication adherence: Its importance in cardiovascular outcome. Circulation. 2009; 119: 302835. PMid:19528344 http://dx.doi.org/10.1161/CIRCULATI ONAHA. 108.768986

[15] White S, Bissell P, Anderson C. A qualitative study of cardiac rehabilitation patients' perspective on taking medicines: Implications for the "medicines-resistance" model of medicine-taking. BMC Health Serv Res. 2013 Aug; 13(302): 1-8. http://dx.doi.org/10.1186 /1472-6963-13-302

[16] Jackevius CA, Li P, Tu JV. Prevalence, predictors, and outcomes of primary nonadherence after acute myocardial infarction. Circulation 2008; 117: 1028-36. PMid:18299512 http://dx.doi.org/10.11 61/CIRCULATIONAHA.107.706820

[17] McDonald HP, Garg AX, Haynes RB. Intervention to enhance patient adherence to medication perceptions: Scientific review. JAMA Dec. 2002; 288(22): 2868-79. http://dx.doi.org/10.1001/j ama. 288.22.2868

[18] Ryan AA. Medication compliance and older people: A review of the literature. Int J Nurs Stud. 1999 Apr; 36(2): 153-62. http: //dx.doi.org/10.1016/S0020-7489(99)00003-6

[19] Wu JR, Chen CH, Yek YL. Factors influencing medication compliant behaviors in elderly patients. Chang Gung Nursing Journal. 2002; 13(2): 166-74. 
[20] Hu WY, Tseng CD, Tai YT, et al. An exploration of the drugcompliant behaviors and associated factors of hypertensive patients. Chinese Journal of Public Health. 1996; 15(4): 319-31.

[21] Dulmen S, Sluijus E, van Jijk L, et al. Patient adherence to medical treatment: A review of reviews. BMC Health Serv Res. 2007 Apr; 7: 55. http://dx. doi.org/10.1186/1472-6963-7-55

[22] Liu SJ. An exploration of the drug compliant behaviors and associated factors of elderly people with chronic disease. The Journal of
Nursing Research. 1999; 7(6): 581-92.

[23] Hu WY, Tai YT, Yu PJ, et al. An exploration of the drug compliant behaviors and influenced factors of elderly hypertensive patients. Tzu Chi Medical Journal. 1999; 11(3): 227-35.

[24] Kerse N, Buetow S, Mainous III AG, et al. Physician-patient relationship and medication compliance: A primary care investigation. Ann Fam Med Sep-Oct. 2004; 2(5):455-61. http://dx. doi .org /10.1370/afm.139 